\title{
REGURGITATION IN ANAESTHESIA: A REPORT ON SOME EXPLORATORY WORK WITH ANIMALS
}

\author{
J. G. Robson, F.F.A R.C.S. (eNG.), and P. WeLt, M.D. ${ }^{1}$
}

IN 1956, Edwards, Morton, Pask, and Wylie (1) in a report on deaths occurring under anaesthesia revealed that 23 per cent of those which were undoubtedly due to the anaesthetic or the anaesthetist were caused by the inhalation of regurgitated or vomited material. Of twenty-nine obstetrical deaths 52 per cent were due to this cause.

Thése authors indicated that such deaths may always be prevented by ensuring that the stomach is emptied of fluid and is kept empty during anaesthesia. This measure implies that an intragastric tube rnust be used efficiently. Since the use of such a tube is not a routine matter, it also implies that the selection of patients in whom it is used should be faultless.

For the purposes of this paper active vomiting is not of immediate interest because in such patients the lungs are usually protected by active reflexes. Its occurrence is also most obvious. Regurgitation can occur when the reflexes are active, but deaths are most likely to occur when reflexes are subdued by muscle relaxants, deep anaesthesia, or local analgesia of the larynx, and regurgitation is not immediately obvious.

The stage is set for regurgitation when: (1) there is fluid in the stomach; (2) the pressure difference between the stomach and the pharynx is sufficient to overcome the mechanism which is responsible for retaining fluid in the stomach. The pressure difference is determined by the intragastric and the intrathoracic pressures. Depending on posture the hydrostatic pressure of fluid in the oesophagus plays a part. Thıs was recognized by Morton and Wylie (2) in 1951.

\section{The Normal Mechanism}

The mechanism which prevents regurgitation up the oesophagus is a matter of controversy. The currently expressed views of the anatomy of the lower oesophagus seem to be those of Lerche (3), modified by those of Gould and Barnhard (4), who hold that there is a functional sphincter mechanism in the oesophagus which is responsible for closure. Other mechanisms have, however, been postulater by many authors. O'Mullane (5) and Nuta (6) believe that there is an intrinsic valvular mechanism formed by the gastric mucosa. Allison (7), Poppel (8), and Muller-Botha (9) believe that there is an extrinsic mechanical or positional mechanism; and many believe that more than one mechanism is responsible for closure $(6,10)$. Many physiological contributions have been made to our knowledge of the innervation of the cardiac sphincter in animals and these are all, of course, based on the assumption that a functional smoothmuscle sphincter exists although it is not demonstrable anatomically (11).

${ }^{1}$ Wellcome Research Department of Anaesthesia, McGill University, Montreal. 
From the viewpoint of applied anaesthesia, O'Mullane's is the only attempt to investigate experimentally the cardiac sphincter and it seemed to us that a more fundamental approach was required.

\section{METHODS}

Cats and mongrel dogs were selected for these experiments. Anaesthesia was induced with nitrous oxide, oxygen, and Fluothane, and maintained on oxygen and ether with a non-rebreathing or T-piece technique. In dogs it was administered by endotracheal tube and in cats by a tracheostomy T-tube. Some cats had anaesthesia induced as above and maintained by chloralose, $50-70 \mathrm{mg} . / \mathrm{kg}$. In all experiments anaesthesia was held at the lightest possible level. Fluothane was only used for induction because the animals showed little or no objection to it and a few breaths of it allowed a rapid change-over to ether.

Several procedures were adopted. For dogs an 8-mm. gum-elastic catheter, $32 \mathrm{~cm}$. long, was prepared, bearing a latex balloon at its lower end which was inflatable through the catheter, 'The balloon was $4 \mathrm{~cm}$. long and would accept $20 \mathrm{ml}$. of air without registering a positive pressure. A similar tube made of polythene, $4 \mathrm{~mm}$. in diameter, the balloon being about $1 \mathrm{~cm}$. long and capable of accepting $5 \mathrm{ml}$. of air without pressure rise, was made for cats. The catheters were connected to a syringe which was mechanically filled and emptied by means of a motor-driven cam. The system was variable with respect to the rate of cycling and the volume introduced. A positive pressure wave was produced with symmetrical rise and fall and the system was arranged to come to atmospheric pressure automatically at the end of each cycle. The cycling rate may be determined from the individual figures, but generally one cycle in $21.5 \mathrm{sec}$. was used. This procedure was adopted in order to try to elicit the secondary peristalsis or peristaltic reflex in the lower oesophagus and cardiac sphincter area and to prevent effects due to prolonged distension and the possible accommodation of smooth muscle over the period of the experiment.

In two dogs a large balloon was placed in the stomach so that the intragastric pressure could be artificially raised by its inflation. This was of such a size that it did not register any positive pressure with the volumes used.

In six cats the abdomen was opened and a glass tube sutured into the stomach at the pyloric end. This was used either to fill the stomach with fluid, or to inflate the stomach rhythmically with fluid by means of the cam-driven syringe. In such experiments a rubber tube, $8 \mathrm{~mm}$. in diameter, was introduced into the oesophagus in the neck and pushed well down into its smooth-muscle section. In three, in addition to this preparation, the greater and lesser omenta were dissected free from the stomach and, after readings were obtained with acid and alkali, the stomach was enclosed in polythene film, sutured to the stomach about 1 $\mathrm{cm}$. below the cardia and, at the distal end, round the pylorus. The stomach was thus prevented from dilating beyond its normal empty size. The results appear under the designation "gastric restraint." The fluid used was 0.5 per cent sodium bicarbonate solution or 0.2 per cent hydrochloric acid, kept at $37^{\circ} \mathrm{C}$. The intragastric pressure was recorded by a water-manometer and the break- 


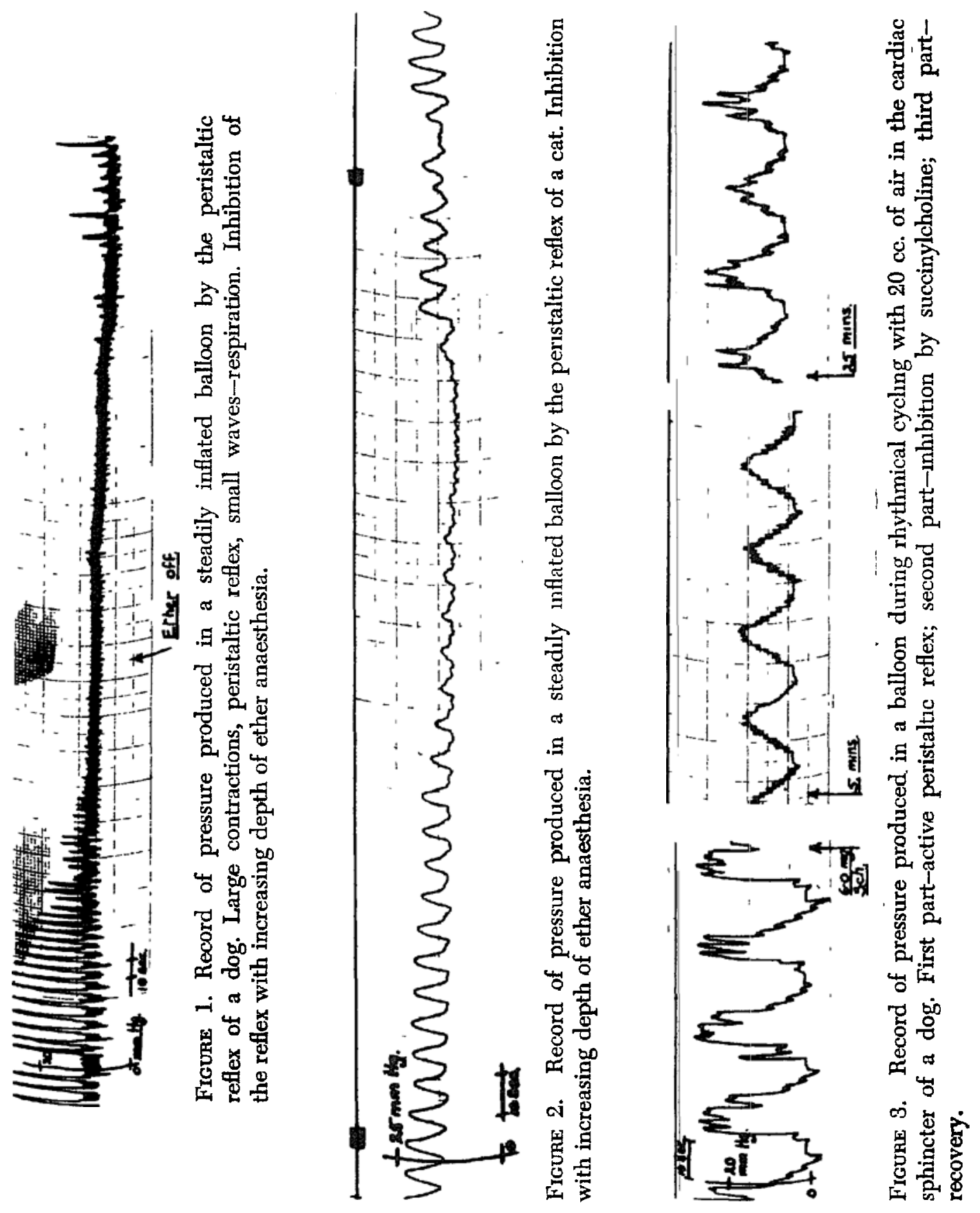



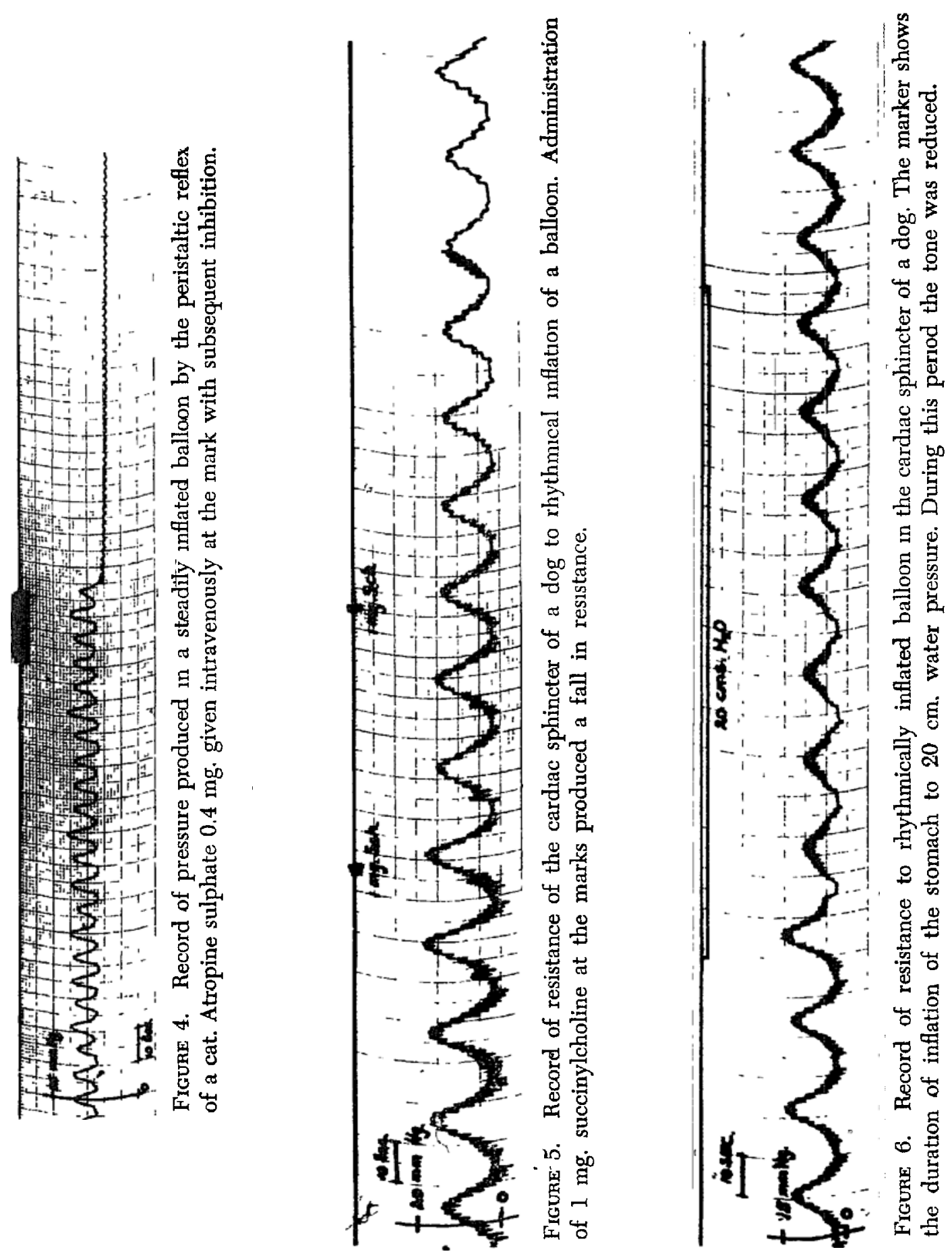
through point was noted by the flow of fluid from the oesophageal tube. The pressure at which this happened is recorded. In each case $10 \mathrm{~min}$. were allowed to elapse after changing the perfusion fluid before recording. This procedure was described by Cannon (12).

All the figures show pressure records which were obtained from these devices by means of Statham P-23-D pressure transducers, Edin-type 8110 carrieramplifiers, and Edin ink-writing oscillographs. Where the records are paired, they were recorded simultaneously.

This experimental method was designed to supply information on three aspects of the mechanism for retention of material within the stomach. These are: (i) the peristaltic reflex; (ii) the tonus of the cardiac sphincter; (iii) the efficiency of the closing mechanism.

\section{Results}

\section{Peristaltic Reflex}

This is the contraction of gut in response to direct distension of the lumen. In the oesophagus the primary peristaltic wave occurs in response to swallowing. The peristaltic reflex is independent of any voluntary action and is initiated by the presence of food or fluid in the lower part of the oesophagus, or by distension of the lumen.

In most of these animals the peristaltic reflex could be elicited by irhythmic inflation of the balloon when it would not respond to steady pressure. In some animals steady inflation of the balloon would maintain the reflex in action for prolonged periods.

Figure 1 shows the peristaltic reflex in response to a steadily maintained balloon pressure of about $8 \mathrm{~mm}$. $\mathrm{Hg}$ in a dog under light ether anaesthesia. The record shows the effect of deepening anaesthesia, with recovery of the reflex on lightening anaesthesia. The respiration does not alter to any extent. Figure 2 shows the ef:ect of ether on the peristaltic reflex of a cat.

Figure 3 shows an active peristaltic reflex in response to rhythmic inflation of the balloon in a dog under light ether anaesthesia. On the intravenous administration of $6 \mathrm{mg}$. of succinylcholine, which in this animal was sufficient to abolish respiration for $25 \mathrm{~min}$., the peristaltic reflex disappeared, to return a short time before respiration became adequate.

Figure 4 shows the peristaltic reflex in response to steady inflation of a balloon at about $12 \mathrm{~mm} . \mathrm{Hg}$ in the cardiac sphincter of a cat under light ether anaesthesia. At the mark, $0.4 \mathrm{mg}$. of atropine sulphate was given intravenously, with prompt cessation of activity.

\section{Tonus of the Cardiac Sphincter}

This we assumed to be the resistance offered o stretch.

In Figure 1 it will be seen that with deepe aing anaesthesia, although the peristaltic reflex was abolished, the tone of the sp.incter did not diminish. Figure 5 shows the response to rhythmic inflation of the cardiac sphincter of a dog. Anaesthesia with ether was deep enough to abolish the peristaltic reflex because it was found (Fig. 3) that when this reflex was active it was difficult to estimate 
tone. At each mark $1 \mathrm{mg}$. of succinylcholine was administered intravenously. The resistance of the sphincter declined from $18 \mathrm{~mm}$. $\mathrm{Hg}$ to $12 \mathrm{~mm}$. $\mathrm{Hg}$.

Figure 4 shows a progressive fall in tone of the cardiac sphincter of a cat following administration of atropine, the pressure dropping from $12 \mathrm{~mm}$. $\mathrm{Hg}$ to $8.5 \mathrm{~mm}$. $\mathrm{Hg}$.

Figure 6 shows the resistance of the cardiac sphincter of a dog to rhythmic inflation. The maximum resistance developed in the control period was $13 \mathrm{~mm}$. $\mathrm{Hg}$. The stomach was inflated to $20 \mathrm{~cm}$. of water pressure at the mark and the resistance to inflation fell to $7-8 \mathrm{~mm}$. $\mathrm{Hg}$. On deflation of the gastric balloon the sphincter recovered its tone.

\section{Over-all Efficiency of the Closing Mechanism}

As the tonus and reflex activity of the cardiac sphincter are perhaps only a part of the closing mechanism, it was thought to be worthwhile to find the pressure necessary to cause reflux from the stomach in various circumstances.

Figure 7 shows two traces, the upper being the maintained intragastric pressure and the lower the intra-oesophageal pressure of a cat under chloralose anaesthesia. The deflections are due to respiration and in the early part of the trace are opposite in sign. The intragastric pressure varied from $0.5 \mathrm{~mm}$. $\mathrm{Hg}$ to 3.5 $\mathrm{mm}$. Hg. Atropine $0.4 \mathrm{mg}$. was given intravenously $5 \mathrm{~min}$. before and in the middle of the trace the intra-oesophageal pressure rose to equal the intragastric pressure, the respiratory pressure variations then having the same sign. This showed that the sphincter became incompetent.

Figure 8 shows in the upper trace the resistance of the upper half of the stomach of a chloralosed cat to rhythmical inflation with $20 \mathrm{ml}$. of saline; and in the lower trace the intra-oesophageal pressure. The waves due to the cycling mechanism in the upper trace are obvious. The coarse waves in both traces are due to respiration and the fine higher frequency waves in the lower record are due to the cardiac impulse. Atropine $0.4 \mathrm{mg}$. was given intravenously at the mark and within about $30 \mathrm{sec}$. the sphincter became incompetent. The oesophageal pressure rose and in the upper trace the syringe was unable to withdraw a full charge from the stomach so that the recorded pressure dipped abruptly below zero. An inspection of the intra-oesophageal pressure trace will show that slow leakage into the oesophagus occurred before it became grossly incompetent.

Table I shows the opening pressures of the sphincter mechanism of three cats, with acid and alkaline perfusion fluid. It will be noted that the resistance to opening is approximately doubled by changing from alkali to acid. In the column designated "gastric restraint" these again are approximately doubled.

TABLE I

\begin{tabular}{lccc}
\multicolumn{1}{c}{ Perfusing fluid } & Opening pressures of sphincter mecharism \\
(cm water)
\end{tabular}




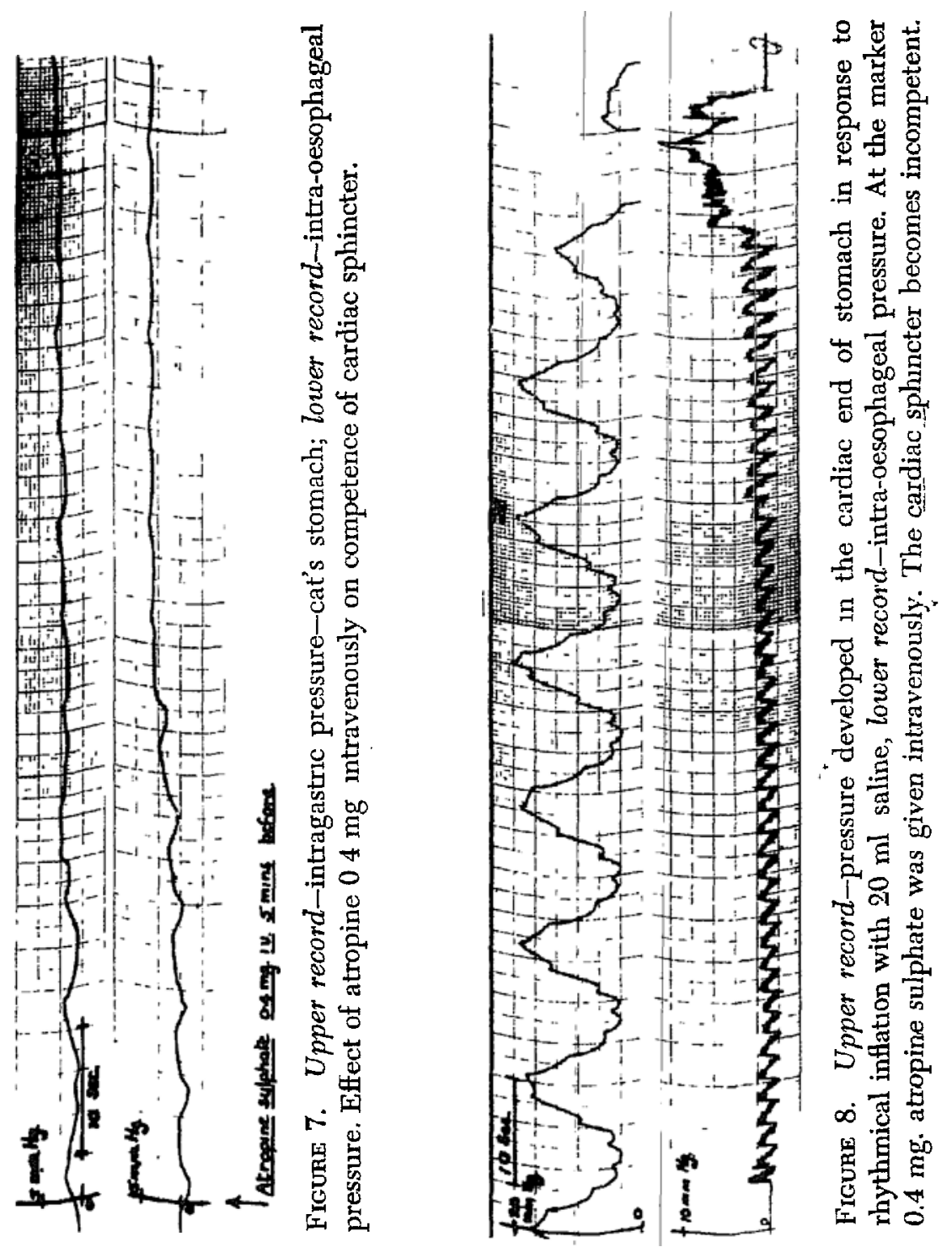




\section{Discussion}

The results shown are extracted from experiments on twelve cats and six dogs. They may be taken as representative findings in a preliminary series of experiments. The species difference merits some discussion. The structure of the oesophagus of the cat is similar to that of man and it may be expected to function in a somewhat similar way. However, the cat differs from man in sensitivity to many drugs and, in particular, is more resistant to atropine. The oesophagus of the dog is composed wholly of striped muscle which has a motor innervation from the vagus. Myoneural blocking agents in the dog, therefore, produce flaccid paralysis of the oesophagus. We believe, however, that in these experiments the balloon lay partly within the cardiac sphincter of the dog. Flaccidity of the area did not occur with succinylcholine although the decline in resistance may indicate that the balloon lay partly within the oesophagus.

During other experiments the cardiac sphincter of the cat was examined directly from below by means of a cystoscope while the stomach was progressively distended with fluid. It was then obvious that distension itself must play a large part in the competence of the mechanism. The attempt to raise the intragastric pressure by filling the stomach with fluid resulted not only in a rise of pressure but, in particular, in the distraction of the gastric mucosal folds from the cardiad orifice. It was decided that this factor could be evaluated by preventing gastric distersion when the intragastric pressure was raised. The results shown in Table I indicate that distension, as a factor in the efficiency of the closing mechanism, is important. That gastric distension may also reflexly diminish the tone of the sphincter is shown by Figure 6 . The figures (Table I) obtained with acid and alkaline perfusion fluid are consistent with those obtained by Cannon. In view of the gross gastric distension produced during these experiments, which has been demonstrated to interfere with some mechanical factors it is likely that this is a direct effect on the cardiac sphincter. The reaction of the gastric contents apparently influences one mechanism of closure.

The peristaltic reflex appears to be a secondary mechanism to prevent regurgitated material from travelling up the oesophagus. This preliminary work indicates that at least two of the drugs commonly used in anaesthesia can inhibit this reflex. The tone, as measured by the method described, is reduced by the same drugs.

In the problem of regurgitation during clinical anaesthesia the relief of gastric distension so that the stomach at least returns to a normal size may be the most important function of a stomach tube. The routine use of atropine in preanaesthetic medication deserves careful consideration.

\section{SUMMARY}

The results of some experimental work with the cardjac sphincter mechanism of cats and dogs are reported. Several methods of investigation were employed. (a) The peristaltic reflex of the lower end of the oesophagus was elicited by steady or rhythmic inflation of a balloon in the area. The tone was also 
determined. (b) The compliance of the cardiac sphiricter to perfusion from the stomach was examined, with and without gastric dilatation. The results indicated that gastric dilatation is an important factor in regurgitation.

The acidity or alkalinity of the gastrict contents mocified the response of the sphincter. Atrojine and ether in the cat and ether and succinylcholine in the dog inhibited the peristaltic reflex and reduced tone.

\section{RÉSUMÉ}

Voici les résultats d'un travail expérimental sur le mécanisme sphinctérien du cardia chez les chats et les chiens. Nous avons employé plusieurs méthodes de recherche: (a) Nous avons provoqué un péristaltisme réflexe de la partie inférieure de l'oesophage en plaçant dans cette région un ballon gonflé en permanence ou en produisant, dans ce ballon, un gonflement rythmé. Nous avons évalué également la force de contraction. (b) Nous avons observé la souplesse du cardia en présence de liquides venant de l'estomac, que l'estomac soit dilaté ou non. Comme résultat, tout laisse croire que la dilatation gastrique est un facteur important dans la regurgitation.

Le sphincter réagit différemment selon que le contenu gastrique est acide ou alcalin. Chez le chat, l'atropine et l'éther et, chez le chien, l'éther et la succinylcholine inhibent l'activité péristaltique réflexe et diminuent le tonus.

\section{REFERENCES}

1. Edwards, G., Morton, H. J. V, Pask, E A; \& Wylte, W. D. Deaths associated with Anaesthesia. Anaesthesia 11. 194 (1956)

2. Monton, H. J. V., \& WyLIE, W. D. Anaesthetic Deaths due to Regurgitation or Vomiting. Anaesthesia 6: 190 (1951).

3. Lerche, W. The Oesophagus and Pharynx in Action. Springfield, Ill. Charles C. Thomas (1950).

4. Gould, D. M., \& Barnhard, H. S. Changing Concepts in the Structure and Function and Disease of the Lower Oesophagus. Am. J Med. Sc. 223: 581 (1957).

5. O'Mullane, E. J. Vomiting and Regurgitation during Anaesthesia. Lancet 1. 1209 (1954).

6. Nuta, J. The Closing Mechanism of the Cardia. Arch Chirurg. Neerlandium 8 280-291 (1956).

7. Alurson, P. R. Reflux Oesophagitis, Slınding Hiatal Hernia and the Anatomy of Repair. Surg., Gynec. \& Obst 92.419 (1951)

8. Poppel, M. H., Lentino, W.; Zaino, C.; \& Jacobson, H. The Closing Mechanism of the Lower Oesophagus in Man. J. A. M. A. 161 (3): 196-198 (1956).

9 Muller-Botha, G. S., Astrey, R., \& Carre, I. J. A Combined Cineradiographic and Manometric Study of the Gastro-Oesophageal Junction Lancet (i) 292 659-662 (1957).

10. Marchand, P. The Gastro-Oesophageal Sphincter and the Mechanism of Regurgitation. Brit. J. Surg. 42 (175): 504-513 (1955).

11. Pernkopf, E., \& Lehner, J. Handbuch der Vergleichenden Anatomie der Wirbeltiere, III, pp. 443-506. Berlin: Urban \& Schwarzenber ( 1937).

12. Cannon, W. B. The Mechanical Factors of D.gestion. New York: Longmans, Green (1911). 